\title{
Implementing SBIRT (Screening, Brief Intervention and Referral to Treatment) in primary care: lessons learned from a multi- practice evaluation portfolio
}

Daniel Hargraves ${ }^{1}$, Christopher White ${ }^{1}$, Rachel Frederick ${ }^{2}$, Margaret Cinibulk², Meriden Peters ${ }^{3}$, Ashlee Young $^{3}$ and Nancy Elder ${ }^{1 *}$ (D)

\section{* Correspondence:}

eldernc@ucmail.uc.edu

'University of Cincinnati

Department of Family and

Community Medicine, Cincinnati,

Ohio, USA

Full list of author information is

available at the end of the article

\begin{abstract}
Background: Screening, Brief Intervention and Referral to Treatment (SBIRT) is a public health framework approach used to identify and deliver services to those at risk for substance-use disorders, depression, and other mental health conditions. Primary care is the first entry to the healthcare system for many patients, and SBIRT offers potential to identify these patients early and assist in their treatment. There is a need for pragmatic "best practices" for implementing SBIRT in primary care offices geared toward frontline providers and office staff.
\end{abstract}

Methods: Ten primary care practices were awarded small community grants to implement an SBIRT program in their location. Each practice chose the conditions for which they would screen, the screening tools, and how they would provide brief intervention and referral to treatment within their setting. An evaluation team communicated with each practice throughout the process, collecting quantitative and qualitative data regarding facilitators and barriers to SBIRT success. Using the editing method, the qualitative data were analyzed and key strategies for success are detailed for implementing SBIRT in primary care.

Results: The SBIRT program practices included primary care offices, federally qualified health centers, school-based health centers, and a safety-net emergency department. Conditions screened for included alcohol abuse, drug abuse, depression, anxiety, child safety, and tobacco use. Across practices, 49,964 patients were eligible for screening and 36,394 pre-screens and 21,635 full screens were completed. From the qualitative data, eight best practices for primary care SBIRT are described: Have a practice champion; Utilize an interprofessional team; Define and communicate the details of each SBIRT step; Develop relationships with referral partners; Institute ongoing SBIRT training; Align SBIRT with the primary care office flow; Consider using a pre-screening instrument, when available; and Integrate SBIRT into the electronic health record.

Conclusions and implications: SBIRT is an effective tool that can empower primary care providers to identify and treat patients with substance use and mental health problems before costly symptoms emerge. Using the pragmatic best practices we describe, primary care providers may improve their ability to successfully create, implement, and sustain SBIRT in their practices.

(Continued on next page)

\section{Biomed Central}

(c) The Author(s). 2017 Open Access This article is distributed under the terms of the Creative Commons Attribution 4.0 International License (http://creativecommons.org/licenses/by/4.0/), which permits unrestricted use, distribution, and reproduction in any medium, provided you give appropriate credit to the original author(s) and the source, provide a link to the Creative Commons license, and indicate if changes were made. The Creative Commons Public Domain Dedication waiver (http://creativecommons.org/ publicdomain/zero/1.0/) applies to the data made available in this article, unless otherwise stated. 
(Continued from previous page)

Keywords: SBIRT (Screening, Brief Intervention, Referral to Treatment), Primary care, Substance abuse, Alcohol abuse

\section{Background}

Substance use and mental health disorders are major global health issues. Worldwide, an estimated 240 million adults suffer from alcohol use disorder. Almost a quarter of adults use tobacco, which is responsible for approximately $11 \%$ of deaths in men and $6 \%$ of deaths in women [1]. The USA is currently experiencing an opioid epidemic, with catastrophic public health consequences. In 2015, the number of US drug overdose deaths rose to over 52,000 with $63 \%$ of these involving an opioid [2]. Meanwhile, depression presents one of the highest disease burdens worldwide [3]. Altogether, the disability-adjusted life-years due to mental and substance use disorders have increased by $15 \%$ from 2005 to 2015 [3]. These emerging data stress the need for sustainable, evidence-based public health initiatives that can reduce the impact of these conditions. Screening, Brief Intervention and Referral to Treatment (SBIRT) is a public health framework approach initially used to identify and deliver services to those at risk for the adverse consequences of alcohol abuse [4, 5], but which has been expanded to a number of substance-use disorders, depression, and other mental health conditions $[4,6]$.

Primary healthcare is key to preventing and finding disease early. However, in the USA, it has long been documented that there is insufficient time for all the preventive care needed [7]. SBIRT began in the 1960s as a screening and brief intervention tool to quickly identify those with risky alcohol use, saving time for providers by focusing on the highest need patients $[5,8]$.In the last several decades, research and demonstration projects (funded largely by the US Substance Abuse and Mental Health Services Administration (SAMHSA)) have confirmed that implementing SBIRT can positively impact patients and their communities [4, 9-12]. While not all research has yielded positive effects [3], the US Preventive Services Task Force (USPSTF) felt the evidence was strong enough to begin recommending screening and brief behavioral interventions for alcohol in 2004, and reaffirmed the recommendation in 2013 [13].

These demonstration projects have also recently begun assessing barriers and facilitators to successful SBIRT implementation $[14,15]$, the possibility of financial sustainability from clinical revenue $[16,17]$, and the effectiveness of various team members delivering SBIRT services [18]. Despite all this research, there is limited evidence for transferring this success from funded demonstration projects to day-to-day primary care office practice, or for beginning SBIRT screening in practices without significant external funding. Bernstein et al. describe lessons following a well-funded emergency department (ED) program, including external funding for start-up, local ED staff champions, sustainability planning from the beginning, and creation and maintenance of a robust referral network [15]. Singh et al. interviewed administrators and evaluators from six SAMHSA SBIRT grantee programs and found sustainability after the grant funding ended was related to securing new funding, having champions, adapting and making system changes, and managing program staffing challenges [17].Muench and Holland performed focus groups of team members and physicians in Oregon and Pennsylvania, respectively, during state-funded alcohol SBIRT projects $[19,20]$. Both sets of researchers noted similar barriers, including 
time constraints, limited access to treatment, ongoing funding and reimbursement concerns, and limited knowledge and self-efficacy. While these studies provide a framework for primary care practices, they all come from large, well-funded projects where previously developed SBIRT was implemented in practices. While Dwinnels describes successful outcomes of a small SBIRT program in a regional community health center, he does not describe its sustainability, nor the factors associated with success [6].

Too many people today are not receiving the treatment they need for substance use and other mental health problems [21], and the growing opioid epidemic is a public health emergency [22]. Primary care is the entry to the healthcare system for the majority of patients across the globe. SBIRT offers great potential for primary care physicians and their staff to identify patients with risky substance use and early symptoms of mental illness and assist in their treatment. However, there is a need for pragmatic "best practices" for implementing SBIRT in primary care offices geared toward frontline providers and office staff. In 2014, The University of Cincinnati Department of Family and Community Medicine partnered with Interact for Health, a greater Cincinnati-based independent foundation, in evaluating SBIRT programs in 10 primary healthcare locations. From this work, we developed practical guidance for primary care practices to assist with developing and implementing SBIRT programs to help them address important public health issues in their communities.

\section{Basics of SBIRT}

In the last 30 years, the SBIRT model has developed increasing function and utility. SAMHSA describes the three components of SBIRT as follows:

- Screening quickly assesses the severity of substance use and identifies the appropriate level of treatment.

- Brief intervention focuses on increasing insight and awareness regarding substance use and motivation toward behavioral change.

- Referral to treatment provides those identified as needing more extensive treatment with access to specialty care [23].

The SBIRT model has continued to grow due to its ability to be built on one of any validated screening instruments for a number of substance and mental health problems, be implemented in a variety of healthcare settings, be performed by a myriad of care team members, and be adapted for a number of culturally diverse populations [18, 24, 25]. For several conditions, "pre-screens" have been validated that allow for rapid, universal screening, followed by more focused full screens $[26,27]$.This has decreased the amount of time needed for screenings in primary care and other general populations. Because of the variety of conditions screened for, and the many settings where SBIRT can occur, there are no good population rates for its actual use, although a 2011 SAMHSA white paper did review the growing evidence for SBIRT's effectiveness [25].

\section{Screening in primary care project}

Between 2014 and 2016, Interact for Health awarded small grants (all US\$60,000 or less) for the implementation of 10 SBIRT programs throughout the greater Cincinnati and Northern Kentucky region in an effort to reduce the number of people with risky 
substance use, anxiety, and depression. Unlike many previous SBIRT studies [19, 28, 29], each practice chose the condition or conditions for which they would screen, the screening tools, and how they would provide brief intervention and referral to treatment within their setting. An evaluation team from the University of Cincinnati's Department of Family and Community Medicine (UC DFCM) communicated with each practice in an iterative process throughout the grant period and collected quantitative and qualitative data regarding facilitators and barriers to the SBIRT process.

\section{SBIRT practice descriptions}

The SBIRT practices included primary care practices (family medicine and general internal medicine), federally qualified health centers (FQHCs), school-based health centers (SBHCs), and a safety-net emergency department (Table 1). Six of the practices screened for a single condition, while four practices screened for two to four conditions.

\section{Program evaluation methods}

Individual SBIRT programs varied in length from 9 to 18 months. The UC DFCM evaluation team met with each practice prior to the start of their program to help them develop process flowcharts that captured the corresponding action and personnel for each stage of SBIRT (Fig. 1). They then collected quarterly data via an online reporting system. Data collected

Table 1 Details about Screening, Brief Intervention and Referral to Treatment programs from the Interact for Health SBIRT Portfolio

\begin{tabular}{|c|c|c|c|c|c|c|c|c|}
\hline & \multicolumn{6}{|c|}{ Condition(s) screened } & \multirow[t]{2}{*}{ Pre-screen } & \multirow[t]{2}{*}{ Full screen } \\
\hline & $\overline{\text { Alcohol }}$ & $\begin{array}{l}\text { Substance } \\
\text { use }\end{array}$ & Depression & Anxiety & Tobacco & $\begin{array}{l}\text { Child } \\
\text { safety }\end{array}$ & & \\
\hline $\begin{array}{l}\text { Primary Care } \\
\text { Prac. } 1\end{array}$ & $\bullet$ & $\bullet$ & & & & & & $\begin{array}{l}\text { AUDIT, } \\
\text { DAST-10, } \\
\text { CRAFFT }\end{array}$ \\
\hline $\begin{array}{l}\text { Primary Care } \\
\text { Prac. } 2\end{array}$ & & & $\bullet$ & & & & PHQ-2 & PHQ-9 \\
\hline $\begin{array}{l}\text { Primary Care } \\
\text { Prac. } 3\end{array}$ & & & & & & $\bullet$ & & SEEK \\
\hline $\begin{array}{l}\text { Primary Care } \\
\text { Prac. } 4\end{array}$ & & & & & $\bullet$ & & & $\begin{array}{l}\text { Single current } \\
\text { use question }\end{array}$ \\
\hline $\begin{array}{l}\text { Fed. Qual. Hlth. } \\
\text { Cntr. } 1\end{array}$ & $\bullet$ & & & & & & AUDIT-C & AUDIT \\
\hline $\begin{array}{l}\text { Fed. Qual. Hlth. } \\
\text { Cntr } 2\end{array}$ & $\bullet$ & $\bullet$ & $\bullet$ & & & & $\begin{array}{l}\text { Single alcohol, } \\
\text { drug question } \\
\text { \& PHQ-2 }\end{array}$ & $\begin{array}{l}\text { AUDIT, } \\
\text { DAST-10, } \\
\text { PHQ-9 }\end{array}$ \\
\hline $\begin{array}{l}\text { Fed. Qual. Hlth. } \\
\text { Cntr. } 3\end{array}$ & $\bullet$ & & & & & & $\begin{array}{l}\text { Single Alcohol } \\
\text { Question }\end{array}$ & AUDIT-C \\
\hline $\begin{array}{l}\text { School-Based } \\
\text { Cntr. } 1\end{array}$ & $\bullet$ & $\bullet$ & $\bullet$ & & & & & $\begin{array}{l}\text { PHQ-9(A), } \\
\text { CRAFFT }\end{array}$ \\
\hline $\begin{array}{l}\text { School-Based } \\
\text { Cntr. } 2\end{array}$ & $\bullet$ & & & & & & & NIAAA \\
\hline $\begin{array}{l}\text { Emergency } \\
\text { Department }\end{array}$ & $\bullet$ & $\bullet$ & $\bullet$ & $\bullet$ & & & PHQ-4 & $\begin{array}{l}\text { NM-ASSIST, } \\
\text { PHQ-9, AUDIT, } \\
\text { GAD-7 }\end{array}$ \\
\hline
\end{tabular}

AUDIT Alcohol Use Disorders Identification Test, NIAAA National Institute on Alcohol Abuse and Alcoholism Screen for Youth, $P H Q-2,4$ or 9 Patient Health Questionnaire, GAD-7 Generalized Anxiety Disorder 7, DAST the Drug Abuse Screening Test, NM-ASSIST National Institute on Drug Abuse Modified Alcohol, Smoking, and Substance Involvement Screening Test, CRAFFT Car-Relax-Alone-Forget-Friends-Trouble, SEEK Safe Environment for Every Kid 


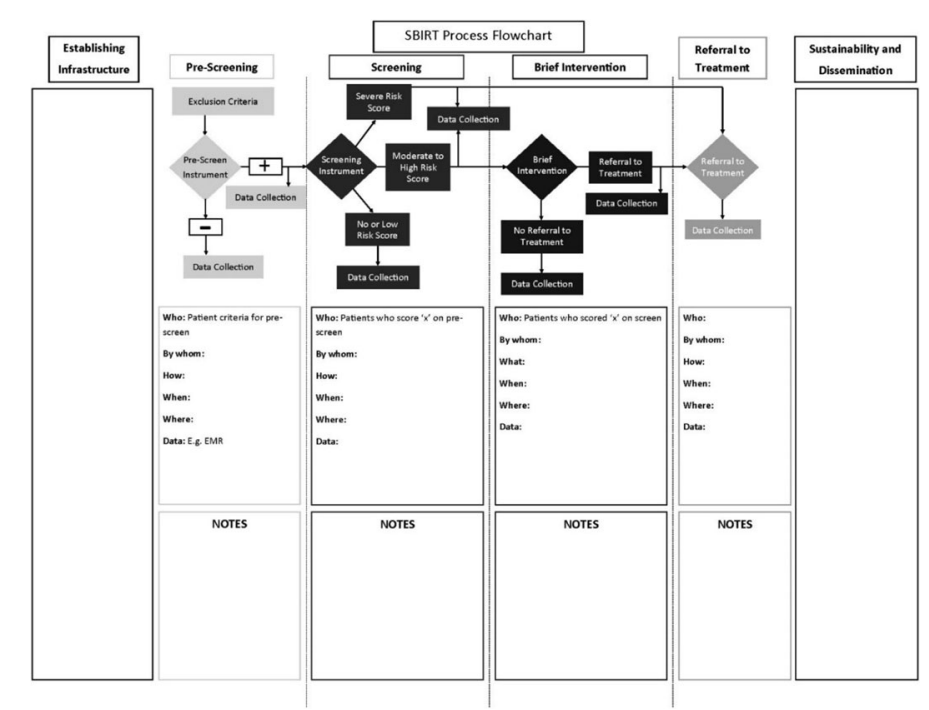

Fig. 1 Graphical flow diagram of the SBIRT process used by practice leaders and staff for planning SBIRT implementation at primary care practices

included (1) number of patients eligible to be screened, (2) number screened, (3) number scoring positive on a screen, (4) number receiving a brief intervention, (5) number referred to treatment, and (6) number confirmed receiving treatment at referral location. In order to study real-time experiences of implementing and running SBIRT, qualitative data were also collected quarterly, both by brief interviews with evaluation staff and online openended questions. The evaluation team also visited most practices at least twice. Questions focused on what worked well during the previous quarter, what needed improvement, and what had changed in regard to data collection and/or SBIRT process flow.

Quantitative data were collated and summarized. Qualitative data, including openended question responses, practice visit notes, and interview notes, were collated and coded using the editing method [30,31]. In this method, while acknowledging the existing literature about SBIRT in primary care $[6,12-14,18,19,28,32,33]$, we sorted the interview data into coding categories derived from the data themselves, explicitly checking them against other categories and the original data, and then searched for patterns and themes. We then returned to the existing literature, and framed our findings as pragmatic best practices for successful implementation of SBIRT in primary care offices.

\section{Quantitative results}

Across all ten program practices, an estimated 49,964 patients were eligible for screening. For all conditions, 36,394 pre-screens and 21,635 full screens were completed (19,687 adults and 1984 youth); 6203 scored positive on the full screens with 3108 brief interventions performed. Practices reported that 1302 referrals to treatment were made, but all practices reported an inability to confidently track confirmation of patients receiving treatment. Alcohol (7361) and substance use (7303) together comprised more than two thirds of the total full screens completed. Details of the SBIRT rates by conditions screened are found in Table 2. 
Table 2 Numbers of patients receiving screening, brief intervention, and referral to treatment by type of condition

\begin{tabular}{|c|c|c|c|c|c|c|c|}
\hline & $\begin{array}{l}\text { Eligible for } \\
\text { screening }\end{array}$ & $\begin{array}{l}\text { Pre-screens } \\
\text { completed }\end{array}$ & $\begin{array}{l}\text { Positive } \\
\text { pre- } \\
\text { screens }\end{array}$ & $\begin{array}{l}\text { Full screens } \\
\text { completed }\end{array}$ & $\begin{array}{l}\text { Positive full } \\
\text { screens }\end{array}$ & $\begin{array}{l}\text { Brief } \\
\text { interventions }^{a}\end{array}$ & $\begin{array}{l}\text { Referrals to } \\
\text { treatment }^{\mathrm{b}}\end{array}$ \\
\hline Alcohol Abuse & 22,360 & 12,697 & 2864 & 7361 & 1840 & $\begin{array}{l}1009 \\
(54.8 \%)\end{array}$ & $\begin{array}{l}209 \\
(20.7 \%)\end{array}$ \\
\hline Drug Abuse & 16,419 & 5581 & 392 & 7303 & 1335 & $\begin{array}{l}442 \\
(33.1 \%)\end{array}$ & $\begin{array}{l}172 \\
(38.9 \%)\end{array}$ \\
\hline $\begin{array}{l}\text { Adolescent Drug } \\
\text { \& Alcohol Abuse }\end{array}$ & 9087 & 1868 & 421 & 794 & 55 & $\begin{array}{l}91 \\
(165.5 \%)\end{array}$ & $\begin{array}{l}25 \\
(27.5 \%)\end{array}$ \\
\hline Depression & 23,861 & 14,062 & 3659 & 3706 & 2294 & $\begin{array}{l}1050 \\
(45.8 \%)\end{array}$ & $\begin{array}{l}693 \\
(66 \%)\end{array}$ \\
\hline Anxiety & 2303 & 2186 & 537 & 74 & 10 & $\begin{array}{l}8 \\
(80 \%)\end{array}$ & $\begin{array}{l}7 \\
(87.5 \%)\end{array}$ \\
\hline Child Safety & 1190 & $\mathrm{n} / \mathrm{a}$ & $\mathrm{n} / \mathrm{a}$ & 1057 & 251 & $\begin{array}{l}193 \\
(76.9 \%)\end{array}$ & $\begin{array}{l}38 \\
(19.7 \%)\end{array}$ \\
\hline Tobacco & 1350 & $\mathrm{n} / \mathrm{a}$ & $\mathrm{n} / \mathrm{a}$ & 1340 & 418 & $\begin{array}{l}315 \\
(75.4 \%)\end{array}$ & $\begin{array}{l}158 \\
(50.2 \%)\end{array}$ \\
\hline
\end{tabular}

apercentage of positive full screens. Some practice sites administered a brief intervention regardless of the full screen score

${ }^{\mathrm{b}}$ Percentage of brief interventions. Some practices bypassed brief interventions and referred some patients directly to treatment

$n / a$ Not applicable as there were no pre-screening tools available

\section{Best practices for SBIRT implementation in primary care Have a practice champion}

This role is responsible for logistical coordination and problem-solving as well as provider accountability. The practice champion does not necessarily need to be the medical director of the practice, but should be someone who is respected by their coworkers. Several studies have cited the need for a champion to encourage staff buyin and engagement and to identify and manage ongoing barriers to program success $[20,34]$. This was consistent with our findings where a program leader who could act as cheerleader, door opener, and bridge between all team members was key to a successfully integrated program. Practice champions who are not in leadership positions need the support and backing of leadership. When the program leader was not a clinical leader, practices that included the medical or nursing director in planning meetings and decision making were more likely to have earlier success. With increasing and competing demands in healthcare settings nationwide, it is necessary to have a point person capable of securing buy-in from the necessary care team members, obtaining initial resources, and ensuring judicious use resources as the program continues.

Utilize an interprofessional team

Incorporating physicians, medical assistants, information technology staff, front desk staff, and other essential staff can aid in identifying challenges and optimizing the process for maximum patient impact. Physicians often mention their lack of time as a major barrier to SBIRT $[14,19]$. Involving an interprofessional team can mitigate the physician's role in favor of shared responsibility among all participants in the SBIRT continuum of care $[18,20,28]$. These interprofessional team members need to be involved from the planning stage. Several of our practices failed to include all team members in the planning process. This resulted in disjointed program rollouts at these practices with wasted resources and the need for additional time and energy to make 
major midcourse corrections. Coordination and communication across disciplines and between diverse skillsets is necessary for seamless and complete delivery of all SBIRT stages.

Define and communicate within the team details of each SBIRT step

Each SBIRT component should be determined based on the needs and availability at the primary care practice as well as provider interest and experience [14, 18, 20, 35]. Early identification of the conditions to be screened and selection of appropriate and validated tools is the first, but essential step, as it will focus and guide the rest of the process. However, our participants found that creating, implementing, and documenting the brief intervention was actually one of the most difficult parts of implementing SBIRT. Practices that created detailed brief intervention expectations (who, when, where, how long, and how often) had more successful outcomes. We also found that practices screening for multiple conditions were unable to offer brief interventions or referrals for multiple positive screens due to time and staff availability. These practices created algorithms that prioritized one positive screen (e.g., drug abuse) over another (e.g., depression) for brief intervention. A limitation of these algorithms is that they were operationalized by screening staff who had limited clinical training and thus were not always patient centered. Primary care practices should consider patient survey fatigue, as well as their own capacity to offer interventions and referrals in a timely manner should they decide to screen for multiple conditions.

Develop relationships with referral partners

All practices failed to implement a referral to treatment that included a communication feedback loop to primary care. Adequate referral partner relationships are necessary for high-risk patients. To better link patients with treatment options after a positive screen and brief intervention, referral partners should be brought to the table during the planning phase of SBIRT. Additionally, other options such as telephonic or telehealth treatment should be explored to increase access to treatment as part of SBIRT [34]. In our region, the lack of referral resources, especially those that can accept a variety of healthcare insurance, were noted as a significant weakness of the implemented SBIRT programs. Additionally, lack of feedback from referral centers made tracking difficult. The confidentiality that is afforded to mental health and substance abuse records further complicated this process. An open line of communication between referring and referral partners and inclusion during SBIRT planning can help to mediate followup barriers, thereby ensuring timely and accurate feedback on treatment linkages. Integrated practices incorporating mental health and/or substance abuse care with primary care also show promise as method for improving both care and communication [36].

\section{Institute ongoing SBIRT training}

Because primary care SBIRT relies on an interprofessional team, training of all involved parties is integral to program success. Staff turnover and insufficient training have been cited as barriers to SBIRT success $[18,20,34]$ and full program implementation may require up to 12 months [18] with continued training and education. As with many primary care offices, our practices were vulnerable to staff turnover. Keeping this in mind, training protocols should be a part of the original planning and program design. SBIRT training should also be incorporated into the onboarding process to maximize success through any staff transition by building broad institutional memory. 


\section{Align SBIRT within the primary care office flow}

As part of the planning phase, a graphical flow alignment diagram that follows the patient through the SBIRT process from beginning to end is useful in assuring that SBIRT fits within existing office flow, such as outlined in Fig. 1. Specifically, flow diagrams that clearly define the pre-screen and screening instrument to be used, scores that lead to brief intervention or directly to treatment, and identify the staff responsible for each step help create an SBIRT program that can more seamlessly integrate into the practice. A graphical flow diagram allows for process refinement prior to implementation. Data collection processes should be included in the operational plan, as feedback is necessary to assure that SBIRT outcomes are being met. Universally, our practices that created, communicated, adapted, and revised the flow diagrams during the planning phase had fewer problems as they rolled out their SBIRT programs. These formal visual maps minimized potential problems before they arose by defining the team and assigning ownership of various SBIRT components.

\section{Consider using a pre-screening instrument, when available}

A major concern by primary care staff who perform the screening of SBIRT is time [20]. Using brief, validated pre-screens can decrease the amount of time spent administering longer instruments, and increase the yield from the full screens. For example, two FQHC practices screened for alcohol abuse, one using the full Alcohol Use Disorder Identification Test (AUDIT) for everyone and one using the AUDIT-C prescreen, followed by the full AUDIT for those with positive pre-screens. The center using only the full AUDIT had a 5\% rate of positive screens, but everyone had to complete the full AUDIT. The center using the pre-screen had $30 \%$ of their patients pre-screen positive, so only this smaller number completed the full AUDIT and 74\% of them had positive full screens. Incorporation of pre-screening into mature SBIRT programs has been utilized to address concerns regarding sustainability and ensure judicious use of staff time while increasing the number of patients served [34]. Whenever possible, validated pre-screening instruments should be utilized.

\section{Integrate SBIRT into the electronic health record (EHR)}

The ability to track patients through the SBIRT process via the EHR is necessary for documenting patient care, analysis of program impact, and assisting practices with population health by better defining and managing the patient population identified by SBIRT. Applicable coding ensures more accurate billing and allows for potential reimbursement for the screening and brief intervention which has been noted as a necessity for program sustainability $[15,16]$. Additionally, other EHR tools such as automated reminders increased the number of patients screened at our program practices. The EHR needs to clearly flag or highlight positive screens to ensure that brief interventions are delivered [37]. Attention must be paid to the EHR integration during the planning phase, however, or lost revenue and poor outcome documentation can sink a program before it becomes established.

\section{Discussion}

As initial programmatic and research funding for SBIRT ended, significant questions still remained about how to create and maintain sustainable SBIRT programs in primary care settings. With the USPSTF supporting the regular use of SBIRT for alcohol abuse [13], and strong evidence for SBIRT growing for other conditions [6, 9-12], primary care offices need 
practical guidance for how best to create and implement SBIRT programs. Since the literature has done a better job of describing barriers to SBIRT than facilitators [5, 10, 14, 16, 17, $19,20,24,34,38]$, we took the lessons learned from our qualitative evaluation of 10 diverse practices and created 8 pragmatic best practices. Many of these are further evidence supporting existing recommendations. For example, the need for practice champions, creating a robust referral network, planning for sustainability, and using an interprofessional team have been described in the SBIRT literature $[15,17,18,28]$. We have added, however, specific details gleaned from working with practices that created SBIRT programs internally, with minimal external funding, in order to provide guidance for primary care physicians, staff and administrators interested in implementing their own SBIRT program.

There are limitations to our study. The 10 practices were selected through a competitive grant process by the community agency, Interact for Health, and therefore might be different than other practices in the community. The greater CincinnatiNorthern Kentucky region is a mid-sized metropolitan region in the midwest USA and is likely different in primary care and clinical practice than other locations in the country. And while the program was created for screening in primary care, the funder included practices such as a safety-net emergency department that many would not consider a primary care location. However, most of the practices were family medicine or general internal medicine offices, school-based clinics, or community health centers. The qualitative findings were consistent with findings from the medical literature [15, $17,18,20]$ making it likely that the practical best practices from these practices will be of value to primary care practices seeking to implement SBIRT.

\section{Conclusion}

The sustainability of an SBIRT program in a primary care setting relies heavily on a well-defined and operationalized plan that fits within office flow. Having a practice champion as well as bringing key members of the team on board in the planning stages improves the chances of successful implementation and continued SBIRT delivery. With our current opioid epidemic, perhaps more than any other time in recent history, primary care must take action and fully participate in identifying patients at risk of substance use and mental health problems. In addition to current community-based prevention programs, public health models like SBIRT in primary care are needed to make a concerted effort against the downstream effects of substance use and mental illness. SBIRT has been shown to be an effective tool that can empower primary care providers to identify and treat this population before costly symptoms emerge. Using the pragmatic best practices we describe, primary care practices may improve their ability to successfully create, implement, and sustain SBIRT programs.

\footnotetext{
Abbreviations

AUDIT: Alcohol Use Disorders Identification Test; CRAFFT: Car-Relax-Alone-Forget-Friends-Trouble; DAST: Drug Abuse Screening Test; ED: Emergency department; EHR: Electronic health record; FQHC: Federally qualified health center; GAD: Generalized anxiety disorder; NIAAA: National Institute on Alcohol Abuse and Alcoholism Screen for Youth; NM-ASSIST: National Institute on Drug Abuse Modified Alcohol, Smoking, and Substance Involvement Screening Test; PHQ: Patient Health Questionnaire; SAMHSA: Substance Abuse and Mental Health Services Administration; SBIRT: Screening, Brief Intervention and Referral to Treatment; SEEK: Safe Environment for Every Kid; UC DFCM: University of Cincinnati's Department of Family and Community Medicine; US: United States; USPSTF: United States Preventive Services Task Force
} 


\section{Funding}

Funding for this evaluation was provided by a grant from Interact for Health and the United Way of Cincinnati (through Interact for Health) to the University of Cincinnati Department of Family and Community Medicine (Nancy C. Elder, MD, MSPH). Staff from the funding agency participated via assisting the evaluation team in accessing data from the SBIRT practices, reviewing and commenting on the ongoing evaluation data and reports, and reviewing and commenting on the final manuscript. The data have been fully shared between the evaluation team and the funder, but the evaluation team (the grantee) created and controlled the evaluation, including the data collection forms, analysis, and writing of the manuscript.

\section{Availability of data and materials}

The datasets generated and analyzed during our current study are available from the corresponding author on reasonable request.

\section{Authors' contributions}

$\mathrm{DH}$ is the project manager who collected qualitative and quantitative data quarterly; assisted in preparing data reports, tables, and figures; assisted with data analysis; and reviewed and edited reports and manuscripts. $\mathrm{CH}$ is a co-investigator who managed the data collection and assisted with team management; assisted in preparing data reports, tables, and figures; assisted with data analysis; and reviewed and edited reports and manuscripts. MC assisted in preparing data reports, tables, and figures, assisted with data analysis, and assisted with writing, reviewing, and editing reports and manuscripts. RF assisted in preparing data reports, tables, and figures, assisted with data analysis, and assisted with writing, reviewing, and editing reports and manuscripts. MP assisted DH, NE, and CW with access to practice personnel for data collection, met regularly with evaluation team providing input into the evaluation process, reviewed ongoing reports, and reviewed and edited the final manuscript. AY assisted $\mathrm{DH}, \mathrm{NE}$, and CW with access to practice personnel for data collection, met regularly with evaluation team providing input into the evaluation process, reviewed ongoing reports, and reviewed and edited the final manuscript. NE is the principal investigator for the project, arranging funding and overseeing financial and data reports, and met regularly with evaluation team and with funding team. NE supervised all team members; assisted in preparing data reports, tables, and figures; assisted with data analysis; reviewed and edited reports, and was the lead author on the final manuscript. All authors read and approved the final manuscript.

\section{Ethics approval and consent to participate}

This evaluation of a community SBIRT program was considered to not be human subject research and was waived from review by the University of Cincinnati Institutional Review Board.

\section{Consent for publication}

Not applicable.

\section{Competing interests}

The authors declare that they have no competing interests.

\section{Publisher's Note}

Springer Nature remains neutral with regard to jurisdictional claims in published maps and institutional affiliations.

\section{Author details}

'University of Cincinnati Department of Family and Community Medicine, Cincinnati, Ohio, USA. ²University of Cincinnati College of Medicine, Cincinnati, Ohio, USA. ${ }^{3}$ Interact For Health, Cincinnati, Ohio, USA.

Received: 20 October 2017 Accepted: 11 December 2017

/ Published online: 29 December 2017

\section{References}

1. Gowing LR, Ali RL, Allsop S, Marsden J, Turf EE, West R, et al. Global statistics on addictive behaviours: 2014 status report. Addiction. 2015;110(6):904-19.

2. Rudd R, Seth P, David F, Scholl L. Increases in drug and opioid-involved overdose deaths_-United States, 20102015. MMWR Morb Mortal Wkly Rep. 2016;65:1445-52.

3. Global Burden of Disease 2015 Disability-Adjusted Life-Years and Healthy Life Excpectancy Collaborators. Global, regional, and national disability-adjusted life-years (DALYs) for 315 diseases and injuries and healthy life expectancy (HALE), 1990-2015: a systematic analysis for the global burden of disease study 2015. Lancet. 2016;388(10053):1603-58.

4. Babor TF, McRee BG, Kassebaum PA, Grimaldi PL, Ahmed K, Bray J. Screening, Brief Intervention, and Referral to Treatment (SBIRT): toward a public health approach to the management of substance abuse. Subst Abus. 2007:28(3):7-30.

5. Saitz R. Screening and brief intervention enter their 5th decade. Subst Abus. 2007;28(3):3-6.

6. Dwinnells R. SBIRT as a vital sign for behavioral health identification, diagnosis, and referral in community health care. Ann Fam Med. 2015:13(3):261-3.

7. Yarnall K, Pollak K, Ostbye T, Krause K, Michener J. Primary care: is there enough time for prevention. Am J Public Health. 2003:93:635-41.

8. Bien T, Miller W, Tonigan J. Brief interventions for alcohol problems: a review. Addiction. 1993;88:315-36.

9. Aldridge A, Linford R, Bray J. Substance use outcomes of patients served by a large US implementation of Screening, Brief Intervention and Referral to Treatment (SBIRT). Addiction. 2017;112(Suppl 2):43-53. 
10. Babor TF, Del Boca F, Bray JW. Screening, Brief Intervention and Referral to Treatment: implications of SAMHSA's SBIRT initiative for substance abuse policy and practice. Addiction. 2017;112(Suppl 2):110-7.

11. Gryczynski J, Mitchell SG, Peterson TR, Gonzales A, Moseley A, Schwartz RP. The relationship between services delivered and substance use outcomes in New Mexico's Screening, Brief Intervention, Referral and Treatment (SBIRT) initiative. Drug Alcohol Depend. 2011;118(2-3):152-7.

12. Humeniuk R, Ali R, Babor T, Souza-Formigoni ML, de Lacerda RB, Ling W, et al. A randomized controlled trial of a brief intervention for illicit drugs linked to the Alcohol, Smoking and Substance Involvement Screening Test (ASSIST) in clients recruited from primary health-care settings in four countries. Addiction. 2012;107(5):957-66.

13. Moyer V. Screening and behavioral counseling interventions in primary care to reduce alcohol misuse: US Preventive Services Task Force recommendation statement. Ann Intern Med. 2013;159

14. Rahm AK, Boggs JM, Martin C, Price DW, Beck A, Backer TE, et al. Facilitators and barriers to implementing Screening, Brief Intervention, and Referral to Treatment (SBIRT) in primary Care in Integrated Health Care Settings. Subst Abus. 2015;36(3):281-8.

15. Bernstein E, Topp D, Shaw E, Girard C, Pressman K, Woolcock E, et al. A preliminary report of knowledge translation: lessons from taking screening and brief intervention techniques from the research setting into regional systems of care. Acad Emerg Med. 2009;16(11):1225-33.

16. Cowell AJ, Dowd WN, Mills MJ, Hinde JM, Bray JW. Sustaining SBIRT in the wild: simulating revenues and costs for Screening, Brief Intervention and Referral to Treatment programs. Addiction. 2017;112(Suppl 2):101-9.

17. Singh M, Gmyrek A, Hernandez A, Damon D, Hayashi S. Sustaining Screening, Brief Intervention and Referral to Treatment (SBIRT) services in health-care settings. Addiction. 2017;112(Suppl 2):92-100.

18. Mertens JR, Chi FW, Weisner CM, Satre DD, Ross TB, Allen S, et al. Physician versus non-physician delivery of alcohol screening, brief intervention and referral to treatment in adult primary care: the ADVISe cluster randomized controlled implementation trial. Addict Sci Clin Pract. 2015;10:26.

19. Holland $\mathrm{CL}$, Pringle $\mathrm{J}$, Barbetti $\mathrm{V}$. Identification of physician barriers to the application of screening and brief intervention for problem alcohol and drug use. Alcohol Treat Q. 2009;27(2):174-83.

20. Muench J, Jarvis K, Vandersloot D, Hayes M, Nash W, Hardman J, et al. Perceptions of clinical team members toward implementation of SBIRT processes. Alcohol Treat Q. 2015;33(2):143-60.

21. Quality CfBHsa. Key substance and mental health indicators in the United States: Results from the 2015 National Survey on Drug Uxe and Health 2016. Contract No.: HHS Publication No. SMA 16-4984, NSDUH Series H-51.

22. Kolodny A, Courtwright DT, Hwang CS, Kreiner P, Eadie JL, Clark TW, et al. The prescription opioid and heroin crisis: a public health approach to an epidemic of addiction. Annu Rev Public Health. 2015;36:559-74.

23. Substance Abuse and Mental Health Services Administration. About Screening, Brief Intervention, and Referral to Treatment (SBIRT) 2017 [Available from: https://www.samhsa.gov/sbirt/about.

24. Manuel JK, Satre DD, Tsoh J, Moreno-John G, Ramos JS, McCance-Katz EF, et al. Adapting screening, brief intervention, and referral to treatment for alcohol and drugs to culturally diverse clinical populations. J Addict Med. 2015;9(5):343-51.

25. Substance Abuse and Mental Health Services Administration. White paper on the evidence supporting Screening, Brief Intervention and Referral to Treatment (SBIRT). Behav Healthcare. 2011; https://www.samhsa.gov/sites/ default/files/sbirtwhitepaper_0.pdf

26. Arroll B, Goodyear-Smith F, Crengle S, Gunn J, Kerse N, Fishman T, et al. Validation of PHQ-2 and PHQ-9 to screen for major depression in the primary care population. Ann Fam Med. 2010;8(4):348-53.

27. Bradley KA, DeBenedetti AF, Volk RJ, Williams EC, Frank D, Kivlahan DR. AUDIT-C as a brief screen for alcohol misuse in primary care. Alcohol Clin Exp Res. 2007;31(7):1208-17.

28. Muench J, Jarvis K, Gray M, Hayes M, Vandersloot D, Hardman J, et al. Implementing a team-based SBIRT model in primary care clinics. J Substance Use. 2013;20(2):106-12.

29. Roy-Byrne P, Bumgardner K, Krupski A, Dunn C, Ries R, Donovan D, et al. Brief intervention for problem drug use in safety-net primary care settings: a randomized clinical trial. JAMA. 2014;312(5):492-501.

30. Crabtree B, Miller W. Doing qualitative research. 2nd ed. Thousand Oaks: Sage; 1999.

31. Miller W, Crabtree BF. Qualitative analysis: how to begin making sense. Fam Pract Res J. 1994;14(3):289-97.

32. Saitz R, Palfai TP, Cheng DM, Alford DP, Bernstein JA, Lloyd-Travaglini CA, et al. Screening and brief intervention for drug use in primary care: the ASPIRE randomized clinical trial. JAMA. 2014;312(5):502-13.

33. Powers J, Benningfield M, Clinton BSBIRT. (Screening for substance use disorder in primary care) — a primary care tool to assess for substance use disorder. Tenn Med E Journal. 2016;2(1):article 5.

34. Vendetti J, Gmyrek A, Damon D, Singh M, McRee B, Del Boca F. Screening, Brief Intervention and Referral To Treatment (SBIRT): implementation barriers, facilitators and model migration. Addiction. 2017;112(Suppl 2):23-33.

35. Del Boca FK, MCRee B, Vendetti J, Damon D. The SBIRT program matrix: a conceptual framework for program implementation and evaluation. Addiction. 2017;112(Suppl 2):12-22.

36. Asarnow JR, Rozenman M, Wiblin J, Zeltzer L. Integrated medical-behavioral care compared with usual primary care for child and adolescent behavioral health: a meta-analysis. JAMA Pediatr. 2015;169(10):929-37.

37. Agley J, Gassman RA, Vannerson J, Crabb D. Assessing the relationship between medical residents' perceived barriers to SBIRT implementation and their documentation of SBIRT in clinical practice. Public Health. 2014;128(8):755-8.

38. Madras BK, Compton WM, Avula D, Stegbauer T, Stein JB, Clark HW. Screening, Brief Interventions, Referral to Treatment (SBIRT) for illicit drug and alcohol use at multiple healthcare sites: comparison at intake and 6 months later. Drug Alcohol Depend. 2009;99(1-3):280-95. 